\title{
Evaluation of Daphnia magna as an indicator of Toxicity and Treatment efficacy of Municipal Sewage Treatment Plant
}

\section{${ }^{1 *}$ TYAGI, V K; ${ }^{2}$ CHOPRA, A K; ${ }^{3}$ DURGAPAL, N C; ${ }^{1}$ KUMAR, ARVIND}

\author{
${ }^{1}$ Department of Civil Engineering, Indian Institute of Technology, Roorkee - 247 667, India \\ ${ }^{2}$ Department of Zoology \& Env. Science, Gurukul Kangri University, Hardwar-249 404, India \\ ${ }^{3}$ Central Pollution Control Board, Parivesh Bhawan, Delhi, India
}

\begin{abstract}
Performance evaluation of wastewater treatment plants (WWTPs) with special reference to toxicity reduction using Daphnia magna straus as test organism is very important to study the likely adverse effects of the treated wastewater on the aquatic ecosystem of receiving waters and to detect common environmentally realistic concentrations of pollutants at different concentration levels and toxicity discriminatory ability to distinguish different degree of toxicity and toxic specificity of the compounds on target organisms. This test can be considered as useful analytical tool for screening of chemical analysis and early warning system to monitor the different operational units of wastewater treatment plants. Interrelationship between COD, SS with respect to Daphnia toxicity (Gd) suggests that improvement of the toxicological quality of wastewater could be linked to the removal of both COD and suspended solids. Both the parameters (COD \& SS) can serve as a regulatory tool in lieu of an explicit toxicological standard. An important feature of this work was to emphasize the significance of toxicity tests. It could help to reduce influent toxicity and thereby avoid impacting microorganisms' population in activated sludge systems. This study shows the difference between using physico-chemical and biological criteria to define the quality or toxicity of wastewater, making it clear that both methods are indispensable and complimentary and support the earlier view that Daphnia magna can serve as a valuable model for bio- monitoring of water pollution and for evaluation of the toxicity of an effluent and risk assessment in an aquatic body, as it is highly sensitive to pollutants. @JASEM
\end{abstract}

Water pollution has become a major threat to the existence of living organisms in aquatic environment. A huge quantity of pollutants in the form of domestic and industrial effluents is discharged directly or indirectly into the water bodies, which has severe impacts on its biotic and abiotic environment (Turk and Turk, 1984). The standard quality of waste effluents has traditionally been based on the control of global parameters such as biochemical oxygen demand (BOD), Chemical Oxygen Demand (COD) or Total Suspended Solids (TSS) according to Council Directive (1991) concerning waste water treatment. The detection of these parameters alone is not sufficient, as the waste water generated from small scale industries may contain large amount of chemicals, many of which may be present in such a low concentrations that these may be beyond detection limit and for many of them even the analytical techniques are inadequate. Secondly, the physico-chemical analysis is not only quite complicated, expensive and time consuming process, but also lacks the information about the additive, antagonistic or synergistic effects of various chemicals on biotic community in aquatic ecosystem (Villegas- Navarro et al., 1999). Therefore, effective tools for the evaluation of negative effects on living organisms are needed. The use of biological assays can provide a direct and appropriate measure of toxicity to complement the physico- chemical measures of quality of wastewaters (Hernando et al., 2005). The toxicity test is one of such parameters, which covers all above shortcomings and can be used as summary parameters (easier, cheaper, effective and less time consuming). The measure of toxicity is an integral view of the sum of all interacting components in the sample. The purpose of regulatory toxicity testing is to produce baseline data for environmental hazard and risk assessment of chemicals, to be used in regulating the discharge of wastewater treatment systems. Bioassay has been extensively used to document toxicity of surface water and evaluate the potential toxicity of discharges into these waters (Blinova, 2000). Numerous studies have been made to understand the toxic effects of waste effluents on fish, but relatively little attention has been paid to their adverse effects on plankton. In view of the importance of cladocerons as an important link in the food chain in aquatic ecosystem, the present work on toxic effects of waste effluents to Daphnia magna straus. Which is highly sensitive to toxic substances, has short generation time, multiplies very rapidly, easily acclimatizes in laboratory condition, cultured in a small space and can be measured in a relatively short period 'APHA, 1998 and GSM, 1989). The use of Daphnia magna in toxicology is accepted in several countries to monitor wastewater treatment systems, to establish quality criteria to determine permissible concentrations of pollutants, limits of impurity in water from natural effluents, and to determine the efficacy of a good sanitation method (Villegas- Navarro et al., 1999).

The acceptance of bioassay toxicity test as an effective analytical tool requires guarantees of 
standardization and validation of the experimental procedure to evaluate its sensitivity, accuracy or precision. In this sense, the main objectives of this work were to assess the utility and validity of toxicity tests and to apply the bioassay toxicity testing for monitoring of wastewater treatment plants.

Site Study: Toxicity evaluation study was carried out at the Common Effluent Treatment Plant located at Mangolpuri industrial area, Phase I, West Delhi Segment. It was worked from November 2001 with a construction cost of about Rs.5.5 Crore. The plant covers an area of $5472 \mathrm{~m}^{2}$. The designed treatment capacity of the plant is $2400 \mathrm{~m}^{3} / \mathrm{d}$, received the waste effluent from around 570 different industrial units includes rubber, food processing, dying, plastic, and electroplating industries.

The treatment system consist of primary treatment with screens, grit chamber, equalization tank, primary clarifier followed by secondary treatment with complete mix activated sludge process, secondary clarifier and tertiary treatment units involving dual media filter (sand filter) and activated carbon filters. Sludge handling facilities consists of gravity thickener, sludge digester and sludge drying beds.

\section{MATERIAL AND METHODS}

Sampling: Wastewater samples were drawn from four different treatment units i.e. receiving chamber (Raw wastewater), after primary and secondary clarifier and clean water sump (finally treated effluent). Composite sampling procedure was adopted as per standard method, to avoid possibly daily variation in the composition of flow. Wastewater samples for toxicological analysis were collected in non- reactive sterilized borosilicate glass bottles of $500 \mathrm{ml}$ capacity. The sample were transported in ice to Bio- Science laboratory of Central Pollution Control Board, Delhi and stored at a temperature of $4^{\circ} \mathrm{C}$ to avoid deterioration. The toxicity test was carried out within next $24 \mathrm{hr}$. (APHA, 1998)

Sampling Analysis: Daphnia tests were conducted following the GSM (1989). COD was defined as the amount of oxygen consumed in the sample during it's chemically digestion over $2 \mathrm{hrs}$ at $150^{\circ} \mathrm{C}$. Data were expressed in $\mathrm{mg} \mathrm{O}_{2} / 1$. Suspended Solids (SS) were estimated as the weight of solids material retained on pre-weighted Whatman filter paper after filtering a known volume of sample and drying the filter / membrane at $105^{\circ} \mathrm{C}$ until a constant weight was reached. Data were expressed in $\mathrm{mg} / \mathrm{l}$.

Daphnia magna used in the experiment were selected

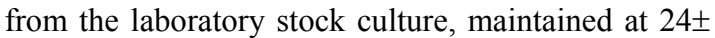
$1{ }^{0} \mathrm{C}$ in 21 glass beaker and were fed on green alga scendesmus substpicatus. Twenty-four hours prior to the test adult daphnia were stored and the young one (neonates) produced from these adults were used in experiment. Dilution water was prepared by using 25 $\mathrm{ml}$ of each stock solution of $\mathrm{KCl}$ (Potassium chloride), $\mathrm{CaCl}_{2} 2 \mathrm{H}_{2} \mathrm{O}$ (Calcium chloride solution), $\mathrm{NaHCO}_{3}$ (Sodium bicarbonate solutions) and, $\mathrm{MgSO}_{4} .7 \mathrm{H}_{2} \mathrm{O}$ (Magnesium sulphate solution) in per liter of double distilled water.

Procedure: The neonates of $1 \mathrm{~mm}$ was collected for the toxicity test by separating the old Daphnids with a nylon sieve plate with a mesh of approximately $1 \mathrm{~mm}$ $\mathrm{x} 1 \mathrm{~mm}$. Daphnids were exposed to different concentration of dilution series (i.e. 1, 2, 3, 4, 6, 8, $12,16,24,32 \ldots \ldots)$ prepared according to German standard method (1989). Five numbers of Daphnids per $20 \mathrm{ml}$ of test solution was taken in $50 \mathrm{ml}$ glass beaker. Tests were run in duplicate. A control set containing dilution water was also run simultaneously. Test was carried out in two phase i.e. Range Finding Test (RFT) and Standard Test. Observation was made for dead or immobilized Daphnids after $24 \mathrm{hrs}$ to $48 \mathrm{hrs}$ for acute toxicity. On the basis of daphnia mortality up to 5 consecutive concentrations have to be selected from RFT dilutions for standard test. The standard test is a confirmatory test, performed to determine Gd value, which is the smallest value of dilution for Test solution in which all daphnia remain capable of swimming. The lowest value of $\mathrm{G}$ ( $\mathrm{Gd}$ value) was reported for the Test liquid in which at least 4 daphnia have retained their swimming ability and indicate Dilution factor (Gd) as test result. In case of more than 1 mortality occurred in check liquid/ control set the experiment was discarded and repeated again (Summary of Test Protocol cited in Table 1). 
Table 1. Summary of Test Protocol for Daphnia Bioassay

\begin{tabular}{|c|c|c|c|c|c|c|c|c|c|c|c|c|c|c|c|}
\hline \multirow{2}{*}{$\begin{array}{l}\text { Sampling } \\
\text { Frequency } \\
\text { (Months/ week) }\end{array}$} & \multicolumn{5}{|c|}{ Daphnia Toxicity (Gd) } & \multicolumn{5}{|c|}{ COD (mg/l) } & \multicolumn{5}{|c|}{ Suspended Solids (mg/l) } \\
\hline & I & $\mathrm{P}$ & $\mathrm{S}$ & $\mathrm{E}$ & $\%$ & I & $\mathrm{P}$ & $\mathrm{S}$ & $\mathrm{E}$ & $\%$ & I & $\mathrm{P}$ & $\mathrm{S}$ & $\mathrm{E}$ & $\%$ \\
\hline Dec I & 16 & 12 & 4 & 1 & 100 & 335 & 296 & 180 & 120 & 64.2 & 134 & 132 & 104 & 24 & 82.1 \\
\hline II & 16 & 12 & 4 & 1 & 100 & 368 & 256 & 136 & 128 & 65.2 & 142 & 134 & 110 & 24 & 83.1 \\
\hline III & 16 & 12 & 4 & 1 & 100 & 396 & 292 & 188 & 140 & 64.7 & 160 & 142 & 98 & 30 & 81.3 \\
\hline Jan & 16 & 8 & 3 & 1 & 100 & 366 & 280 & 168 & 130 & 64.5 & 145 & 136 & 104 & 26 & 82.1 \\
\hline II & 16 & 12 & 4 & 1 & 100 & 350 & 220 & 140 & 124 & 64.5 & 154 & 145 & 110 & 18 & 88.3 \\
\hline III & 16 & 12 & 4 & 1 & 100 & 325 & 236 & 144 & 110 & 66.2 & 148 & 129 & 88 & 12 & 91.9 \\
\hline Feb & 16 & 12 & 4 & 1 & 100 & 342 & 215 & 130 & 110 & 67.8 & 160 & 138 & 106 & 22 & 86.3 \\
\hline II & 16 & 12 & 4 & 1 & 100 & 330 & 260 & 172 & 128 & 61.2 & 188 & 172 & 135 & 32 & 83.0 \\
\hline III & 16 & 12 & 4 & 1 & 100 & 385 & 294 & 190 & 130 & 66.2 & 176 & 166 & 122 & 48 & 72.7 \\
\hline March I & 16 & 8 & 4 & 1 & 100 & 360 & 244 & 164 & 138 & 61.7 & 187 & 166 & 114 & 25 & 86.6 \\
\hline II & 16 & 12 & 3 & 1 & 100 & 310 & 234 & 158 & 120 & 61.3 & 150 & 134 & 92 & 18 & 88.0 \\
\hline III & 16 & 12 & 4 & 1 & 100 & 315 & 220 & 124 & 108 & 65.7 & 177 & 162 & 134 & 28 & 84.2 \\
\hline
\end{tabular}

\section{RESULTS AND DISCUSSION}

Toxicity removal efficiency of CETP: Earlier studies on effluent test using Daphnia magna showed that macro-invertebrates could be used as a sensitive indicator for effluent toxicity study (Verma et al, 2003). The wastewater samples collected from the various treatment units of CETP were analyzed for weekly/ monthly variations from December 2001March 2002. Table 2 gives the descriptive data on sampling frequency, Daphnia toxicity (Gd), Chemical Oxygen
Demand (COD) and Suspended Solids at different treatment levels and the overall plant efficiency w.r.t. to percentage removal of above mentioned parameters.

\begin{tabular}{|c|c|c|}
\hline \multicolumn{3}{|c|}{$\begin{array}{l}\text { Table 2: Descriptive data and removal efficiency of performance parameters at Common } \\
\text { effluent treatment plant, Mangolpuri (Del }\end{array}$} \\
\hline S.No. & Test Type & Static \\
\hline 1. & Temperature & $24 \pm 1^{\circ} \mathrm{C}$ \\
\hline 2. & Light & $\begin{array}{ll}\text { Ambient } & \text { laboratory } \\
\text { illumination } & \end{array}$ \\
\hline 3. & Test vessel & $50 \mathrm{ml}$ glass beaker \\
\hline 4. & Test solution volume & $20 \mathrm{ml}$ \\
\hline 5. & Test organisms/vessel & 5 \\
\hline 6. & Replicate & 2 \\
\hline 7. & Test concentration & $1,2,3,4,6,8,12,16,24,32$ \\
\hline 8. & Feeding regime & No feeding during exposure \\
\hline 9. & Control water & Standard dilution water \\
\hline 10. & Test duration & $24 \mathrm{hrs}$ to $48 \mathrm{hrs}$ \\
\hline 11. & End point & Immobilization / death \\
\hline
\end{tabular}

The variations in Gd, COD and SS concentrations and removal in percentage terms are also illustrated graphically in figs.1, 2 and 3. The mean influent toxicity was Gd- 16. Toxicity after primary, secondary and tertiary treatment units was in the range of $\mathrm{Gd} 8-\mathrm{Gd} 12, \mathrm{Gd} 3-\mathrm{Gd} 4$ and $\mathrm{Gd} 1$ respectively. The toxicity of wastewater is reduced cumulatively from influent to effluent. The mean percentage removal in toxicity after primary, secondary and tertiary treatment units were found to be $29 \%, 76 \%$ and $100 \%$ respectively. It shows that treatment of wastewater up to secondary level is not satisfactory itself to reduce wastewater toxicity completely or its maximum extent. We found the $100 \%$ removal in Daphnia toxicity (Gd) only after tertiary treatment of wastewater. 


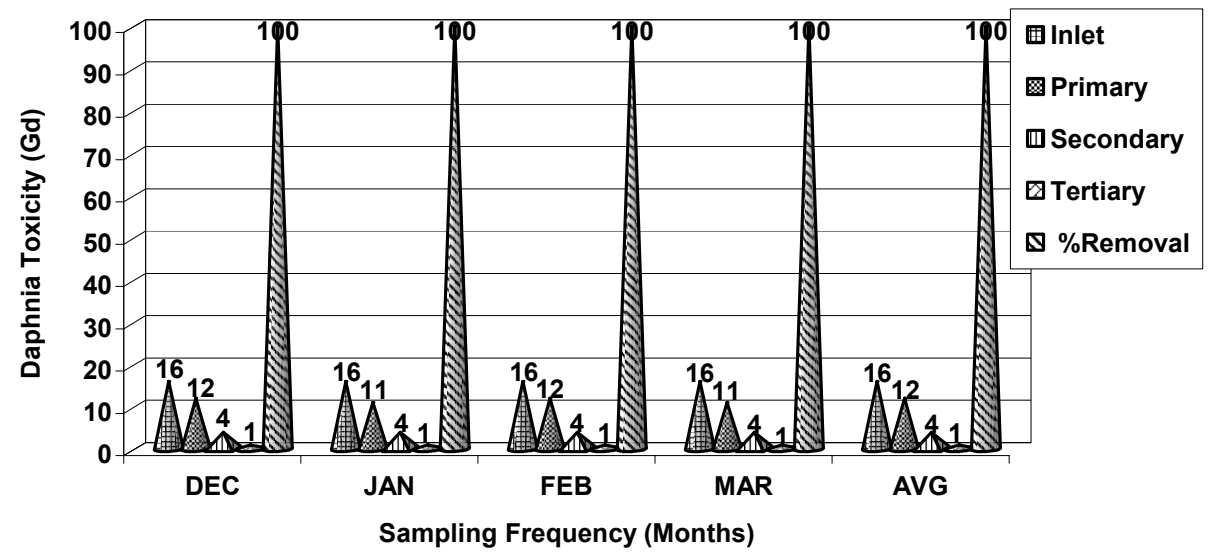

Fig 1: Status of Daphnia toxicity (Gd) at different treatment levels of CETP

The mean influent COD and SS were found in the ranges of $349 \mathrm{mg} / 1$ and $160 \mathrm{mg} / \mathrm{l}$ respectively. After primary, secondary and tertiary treatment both were observed within a mean range of $254 \mathrm{mg} / 1,150 \mathrm{mg} / \mathrm{l}$, $123 \mathrm{mg} / \mathrm{l}$ and $146 \mathrm{mg} / \mathrm{l}, 110 \mathrm{mg} / \mathrm{l} \& 26 \mathrm{mg} / \mathrm{l}$ respectively. The findings revealed that a systematic removal in COD and SS concentration found from influent to effluent. The mean percentage removal in COD and SS after primary, secondary and tertiary treatment level were found to be $27 \%, 57 \%, 65 \%$ and $10 \%, 31 \%$ and $84 \%$ respectively.

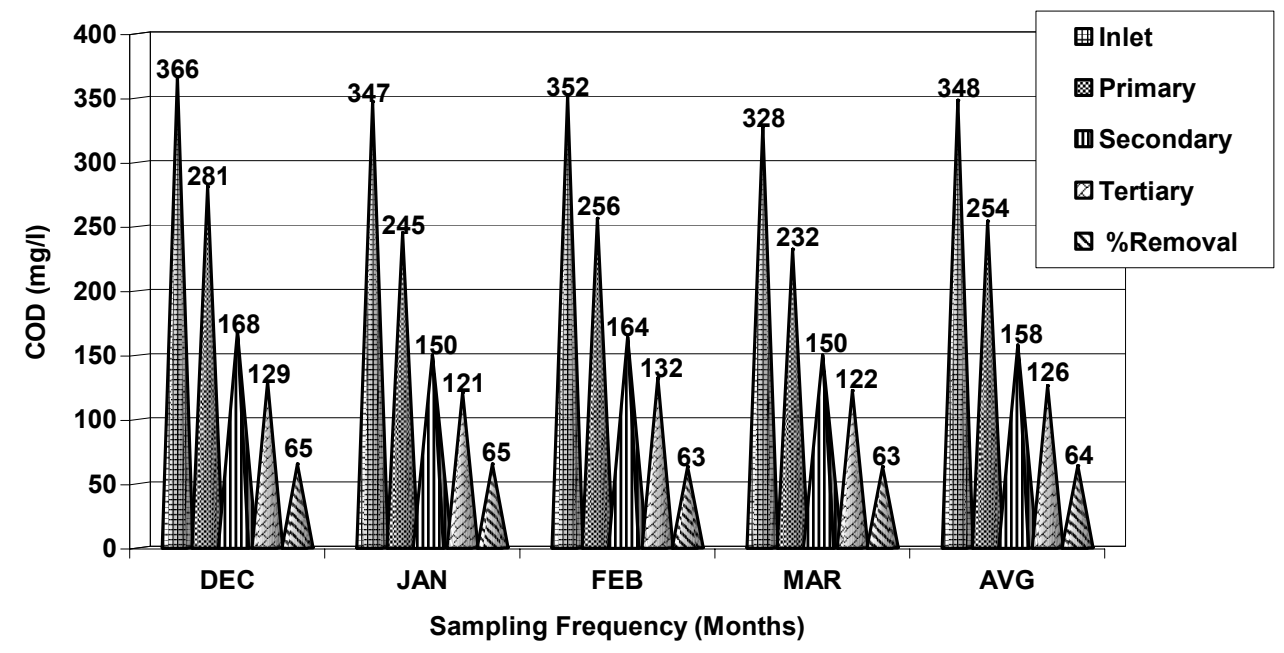

Fig 2: Status of Chemical Oxygen Demand (COD) at different treatment levels of CETP

Thus the observations discloses that COD, SS and Daphnia toxicity $(\mathrm{Gd})$ reduce slightly at primary treatment level and significantly at secondary treatment level, while as the optimal and maximum removal in $\mathrm{Gd}, \mathrm{COD}$ and $\mathrm{SS}$ concentration were found at tertiary treatment level. Figure 4 shows the cumulative percentage reduction of performance parameters at different treatment levels of CETP. 


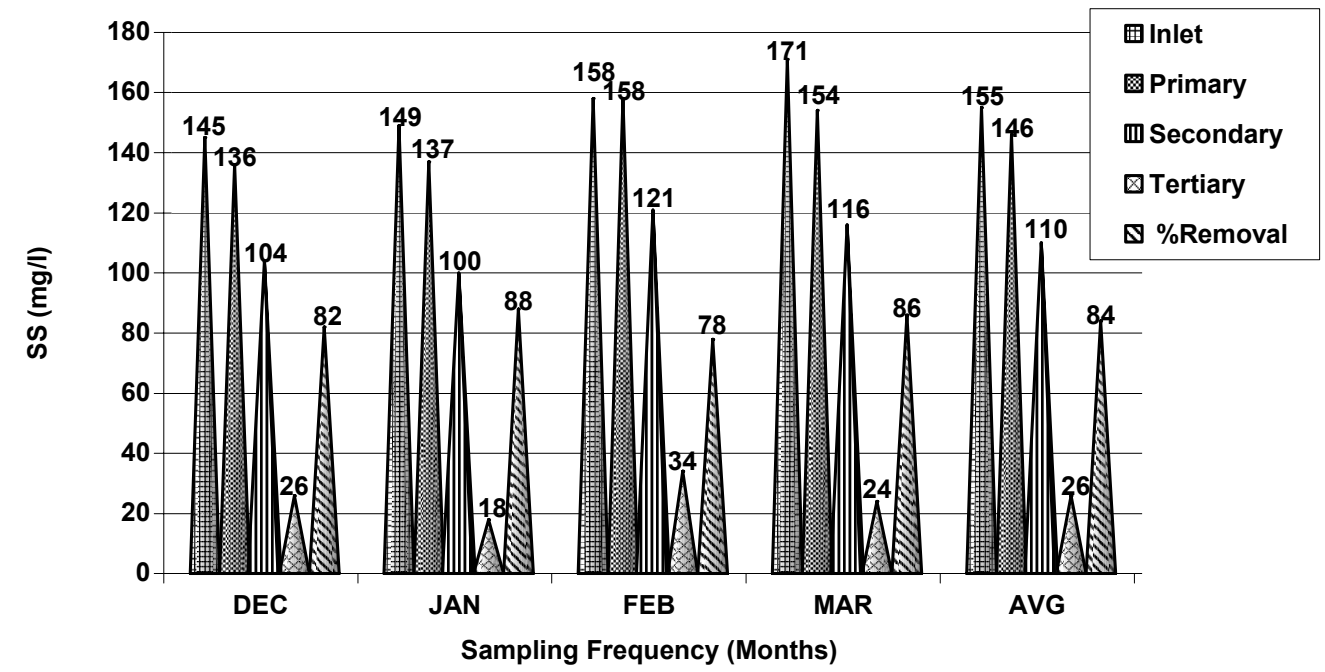

Fig 3: Status of Suspended Solids (SS) at different treatment levels of CETP

Interrelationship between Daphnia toxicity $(G d)$, $C O D$ and SS: On the basis of data obtained we tried to establish relationship between two key wastewater constituents i.e. COD and SS with Daphnia toxicity (Gd). From the plots of fig. 4 and 5 the following relationships were obtained between key parameters,

$\mathrm{Gd}=0.0631 \mathrm{COD}-5.9436\left(\mathrm{r}^{2}=0.899\right) \ldots$ (i)

$\mathrm{Gd}=0.0978$ SS $-2.4465 \quad\left(\mathrm{r}^{2}=0.801\right) \ldots$ (ii)

Both the coefficient of correlation values were found to be varying between $0.8-1$, which indicates relatively good interrelationship between the concerned parameters. For COD there was a positive correlation between Daphnia Toxicity (Gd) removed and COD $\left(r^{2}=0.899\right)$ as shown in fig.5. Suspended solids removal also shows significant correlation to the toxicity removal $\left(\mathrm{r}^{2}=0.801\right)$ as depicted in fig. 6 . It shows that $\mathrm{Gd}$ value could be more strongly correlated to COD than SS. Thus these interrelationships could be helpful in routine monitoring of STPs efficiency.

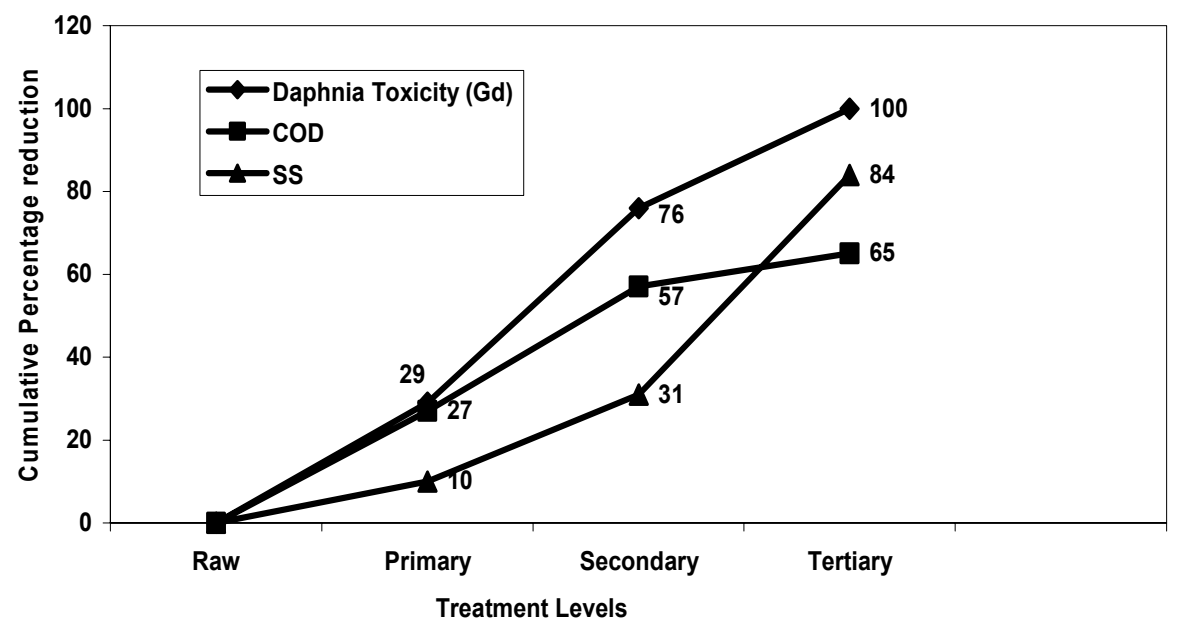

Fig 4: Cumulative reduction of performance parameters at different treatment levels of CETP

The observations revealed that an efficient final clarification step, which eliminates COD and SS in wastewater, plays a central role in toxicity reduction in conventional wastewater treatment system.
Therefore, for up gradation of sewage treatment plant in terms of toxicological quality, the effluent suspended solids and chemical oxygen demand should be as low as possible by providing optimal 
treatment and settling conditions to the aeration and sedimentation tanks. Moreover our results indicate that toxicological pollution to receiving natural waters was not strongly dependent on influent water quality or seasonal variations, instead it was related to the efficiency of treatment processes in removing organic loads i.e. COD and SS. Finally the authors believe that more discussion should be undertaken regarding the efficacy of process requirements versus toxicological quality goal of secondary or tertiary treated water.

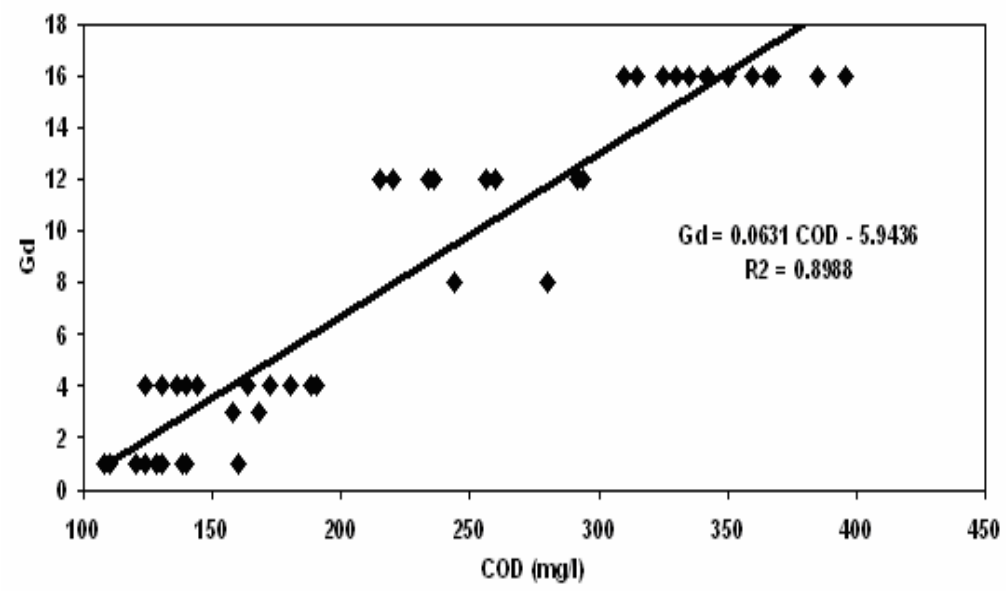

Fig 5: Interrelationship between Daphnia Toxicity (Gd) and Chemical Oxygen Demand

Conclusion: This paper investigates the utility and validity of bioassay toxicity testing for monitoring of wastewater treatment plant. The crustacean Daphnia magna was used as the sensor organism The validation studies indicated that the acute toxicity test can be considered as high sensitivity analytical tools to detect common environmental concentrations of the pollutants. The average Daphnia toxicity (Gd) at inlet, after primary settling tank (PST), secondary settling tank (SST) and tertiary treatment unit were reported as Gd-16, Gd-12, Gd-4 and Gd-1 respectively. However, a cumulative mean percentage removal in toxicity after PST, SST and tertiary treatment units was observed as $25 \%, 75 \%$ and $100 \%$ respectively during all the round of sampling. It revealed that a complete removal in daphnia toxicity (Gd) i.e.100\% had been achieved only after tertiary treatment unit involving Dual Media Filters followed by activated carbon filters. It means that CETP technically reduced the toxicity of wastewater to maximum extent. The results clearly showed that the use of bioassay tests produced additional information about the toxicity potential of industrial discharges and effluents.
Further attempts have been made to establish the relationship between key wastewater constituents i.e. Chemical Oxygen Demand (COD) and Suspended Solids (SS) with respects to Daphnia toxicity (Gd). Of the more common physicochemical parameters, the COD and SS showed a statistically significant correlation with toxicity reduction at different treatment units and can serve as a regulatory tool in lieu of an explicit toxicity standard (to check and improve the operational status of wastewater treatment plants in time). Our investigation showed that toxicity test with the studied species may be used as an effective tool for the assessment of water purification process effectiveness at the wastewater treatment plants. Thus the concerned study sounds that knowledge of the toxicity of effluents can benefit treatment plant operators in optimizing plant operation, protecting receiving water quality, establishing sewer discharge permits and control of toxicity can give more objective baseline data for environmental risk assessment of polluted waters dumped into natural ecosystem. 


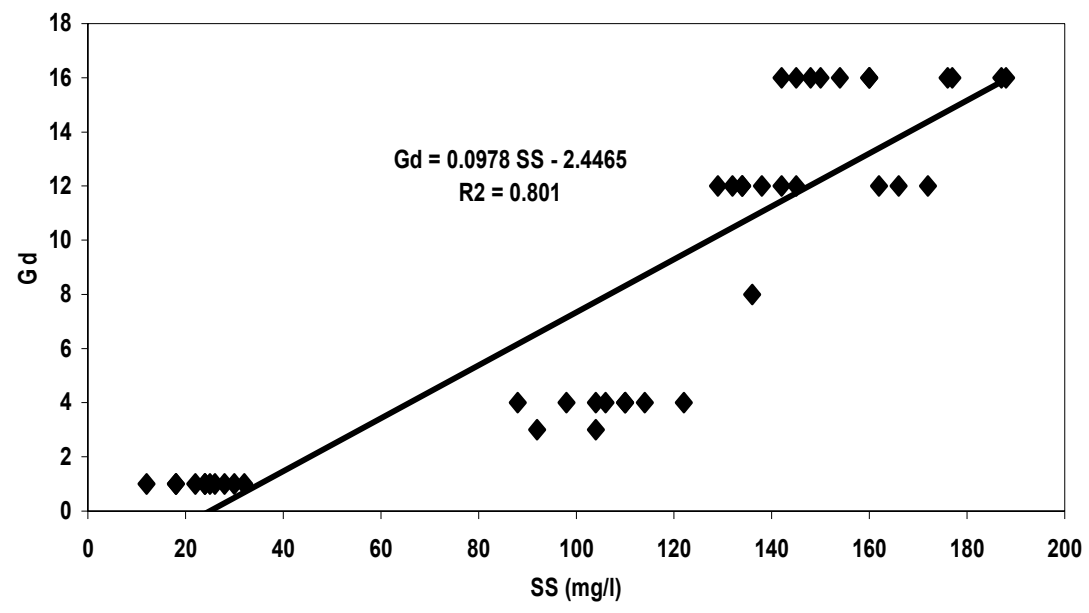

Fig 6: Interrelationship between Daphnia Toxicity (Gd) and Suspended Solids

Acknowledgement: The author is thankful to the authorities of Central Pollution Control Board (CPCB), Delhi for providing facilities, guidance and continuous encouragement during the course of project.

\section{REFERENCES}

APHA, AWWA, WEF (1998). Standards Methods for the Examination of Water and Wastewater, 20th edition, American Public Health Association, American Water Works Association and Water Environmental Federation, Washington, DC 20005- 2605.

Blinova, I (2000). Use of bioassays for toxicity assessment of polluted water. Proceedings of the symposium dedicated to the $40^{\text {th }}$ anniversary of environmental engineering at Tallinn Technical University. 24- 26 September, Tallinn. Tallinn, 149- 154.

Council Directive (1991). Council Dirctive 91/ 271/ EC of 21 May 1991 concerning urban wastewater treatment, Official Journal of European Communities.
GSM (1989) Examination of Water, Wastewater and Sludge, Bio-assays (Group L) Determining Tolerance of Daphnia to Toxicity of Wastewater by way of a Dilution Series, GSM(German Standard Methods)(L-30), DIH-38412, Part 30, March 1989.

Hernando, MD, Fernandez-Alba, AR, Tauler, R and Barcelo, D (2005). Toxicity assays applied to wastewater treatment, Talanta 65, 358- 366.

Turk, J. and Turk, A (1984) Environmental Science, $3^{\text {rd }}$ edition, Saunders College Publishing, USA.

Verma, Y, Ruparelia, SG Hargan, MC and Kulkarni, PK (2003) Toxicity testing of the effluents from dye industries using daphnia bioassay. Journal of Indian Association for Environmental Management, 30: 74-76.

Villegas- Navarro, A, Romero Gonzalez, MC and Rosas Lopez, E (1999). Evaluation of Daphnia magna as an indicator of toxicity and treatment efficacy of textile wastewater. Environmental International.25: 619- 624. 